\title{
When Things Collide: Wayfinding in Professional Writers' Early Career Development
}

\author{
Carl Whithaus - University of California, Davis \\ Jonathan Alexander - University of California, Irvine \\ Karen Lunsford - University of California, Santa Barbara
}

\section{KEYWORDS}

wayfinding; professional writing; writing through the lifespan; post-college writing; writing transfer; metageneric connections

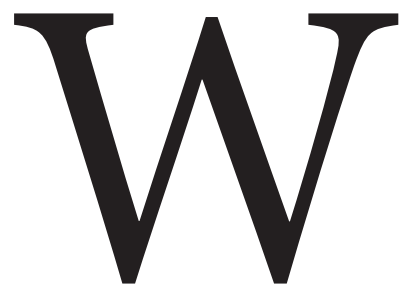

ithout a doubt, paying attention to writers' composing practices after college tells us much about how those practices, as well as writers' meta-cognitive development of knowledges $^{1}$ about their own writing, continue to evolve. Scholars in the field have been undertaking this work, particularly since, as Deborah Brandt argues in The Rise of Writing: Redefining Mass Literacy, writing is overtaking reading as the dominant marker of being literate in our society - becoming the primary "site of intellectual, moral, and civic development" (162). Much of the shift toward emphasizing writing ability as a powerful marker of intellectual development stems from the increasing sophistication required of workplace communicators paired with the social pressures to contribute meaningfully on social media platforms that now constitute a set of popular digital writing publics. Given such a context, scholars in composition and writing studies need to understand how postgraduate writers find their way as composers in and across increasingly complex domains.

More of our alumni than ever before-not just those in writing or humanities majors or even those who anticipate writing a great deal in their professions-are writing and composing more across multiple contexts. Studying such experiences across multiple contexts, not just in particular situations, should tell us much about the changing nature of writing in our alumni's lives and the experiences of alumni as they continue to develop as writers. We have chosen the concept of wayfinding to theorize the experiences of writers as they move among collegiate, professional, and personal activities: the individual sense of continuing potentiality of writing domains, rapidly changing job prospects and requirements, and writers' agency in dealing with the unexpected work demands and sometimes their own desires for what they want writing to do. These alumni articulate how 
they perceive their evolving choices about the kinds of writing available to them, as well as their developing knowledges about writing in multiple domains during the early parts of their professional careers.

In the collection The Lifespan Development of Writing, Charles Bazerman, Arthur N. Applebee, and Virginia W. Berninger argue that the complexity of writing experiences and development has been underestimated. They call for researchers to study how long-term writing development occurs across changing contexts. Recent work, such as a special issue of Literacy in Composition Studies, has explored ongoing literacy development in aging populations, asserting that "studies of older people yield rich information about literacy learning and practice that is usually distanced from the contexts and motives of schooling" (Bowen). The lifespan model of writing development suggests an alternative to transfer or transition as a model. Within the lifespan model, understanding how writers develop is not a question about the transition from one context, such as schooling, to another, such as career. It is rather about the relationships among writers' contexts and writers' sense of their own development across contexts and time.

This stance changes how we as reasearchers approach the dimensions of writing and literacy development, and how those dimensions play across age levels, across time, and across contexts. Along these lines, in our previous article,

"While some writing abilities and knowledges about writing certainly develop in separate spheres, they also develop as part of a continual process that is far from linear and may be significantly more recursive than our current theoretical models account for."
"Toward Wayfinding: A Metaphor for Understanding Writing Experiences," we developed the concept of wayfinding out of our concern that dominant metaphors for studying writing experiences-worlds apart, literacy in the wild, ecologies and networks, and transferemphasized the development of writing skills, strategies, and habits of mind as occurring in discrete domains. While some writing abilities and knowledges about writing certainly develop

in separate spheres, they also develop as part of a continual process that is far from linear and may be significantly more recursive than our current theoretical models account for.

In this article, we continue to explore how wayfinding might allow us an opportunity to map what we have previously identified as writers' "complex and recursive movement in and out of different territories, realms, spaces, and spheres of writing ecologies" (Alexander, Lunsford, and Whithaus, 121). And while we appreciate the forcefulness of models, such as transfer, that seek to account for the particular knowledges of writing that writers develop and move across contexts, we also hope that wayfinding will, as we say, attune us to the "potential transience of the contexts in which people write" and focus our attention also on writers' "fluid ability to not only move among those contexts, but also to create their own niches" to enact and experience the kinds of writing important to them (124). Having offered some initial theoretical propositions in "Toward Wayfinding," we have been collecting data from current students and alumni and developing a schema to understand the many stories that students and graduates tell about their writing lives. In this article, we focus 
on accounts from seven alumni who participated in focus group interviews during 2018-19. These case studies feature alumni representing diverse identities, communities, and backgrounds found among students enrolled at campuses in the University of California system. After graduating, our participants moved around the country and now live on the East Coast, in the Midwest, as well as on the West Coast. They work in a variety of professions including advertising, consulting, education, journalism, and marketing.

We consider the ways in which these writers' accounts are shaping our development of wayfinding as not just a metaphor but a theoretical lens for approaching writing in a complex world. We offer examples of writers' navigating the transition from college to workforce-a frequently studied transition in our field. Using wayfinding as our theoretical lens, we pay attention to the ways in which writers trace the idiosyncratic paths they follow as they draw on knowledge and abilities from different and multiple writing ecologies. Writers draw from writing experiences that include far more than school-based ones. Moreover, focusing on writers' articulated sense of wayfinding honors what knowledges they are building about writing. Our participants appreciate the training they have received but also discover that what they anticipated in post-collegiate writing experiences has to be understood and revised through the unexpected knowledges they develop on the job and through other post-collegiate writing experiences. The examples they offer show us how alumni "find their way" and introduce three emergent themes in our ongoing analysis of wayfinding. Our participants describe their developing literacy journeys as writers: (1) encountering the unexpected, (2) navigating career plans and paths, and (3) seeing beyond the boundaries of writing contexts. In each case, we narrate how wayfinding helps us illuminate the complex dynamics at play as these writers continue to explore how writing is meaningful in their lives.

\section{Transitioning Beyond College: Research from the Field}

Work in the field on students' moving from college to post-collegiate writing domains often focuses on the extent to which current curricula can better prepare students for that transition. Data gathered from longitudinal studies of writers allow scholar-teachers to prompt curricular revision and innovation. We appreciate the creativity of such research, too, in its attempt to track the nuanced ways in which writers develop. For instance, Anne Beaufort's ethnographic studies of college writers moving into the world of work, Writing in the Real World: Making the Transition from School to Work and College Writing and Beyond: A New Framework for University Writing Instruction, constitute some of the most widely cited work in the field on this transition. The former book focuses on the development of writerly expertise that moves from collegiate to professional contexts and forms of writing, and the latter is an in-depth, longitudinal case study of one student making a comparable transition. For Beaufort, these domains constitute important pivot points as student writers move from college into careers.

Broadening the scope of such transitions to include internships, Neil Baird and Bradley Dilger report on how students perceive transfer across domains. Baird and Dilger focus on how student writers are often working in both school and job contexts simultaneously, creating opportunities 
for recursive reflection on their development of writing knowledges as they find their way through different ecologies of communication. Studying such transfer is not easy, especially as researchers broaden domains of possible transfer. Doug Brent succinctly summarizes the challenge of studying such transitions in his article, "Transfer, Transformation, and Rhetorical Knowledge: Insights From Transfer Theory": "If there is doubt about whether students can transfer their rhetorical knowledge and skill to neighboring academic disciplines-what would be known in learning transfer theory as (relatively) near transfer-there is even more doubt about whether they can do so to the professional workplace (far transfer)" (397). While Brent entertains such doubts seriously, he, like others, argues that curricula can indeed "encourage transfer" (398) by fostering reflection, mindfulness, and metacognition. However one approaches the idea of transfer, the navigation from collegiate to postcollegiate writing lives is an intense focus of study in the field.

As important as this work has been, we note how it focuses primarily on curricula and the impact they have on writing development. While we acknowledge the impact of such work, including that of Kathleen Yancey, Rebecca Nowacek, and Linda Adler-Kassner, we are drawn to the domains of learning about writing that lie not just within but outside formal curricular pathways-that is, ways of finding out about writing that are perhaps a bit more idiosyncratic. Even more so, scholars in the field are paying increased attention not just to transfer across formal curricular and professional domains but also to the complex cultural practices of communication and worldbuilding that inform identity, community, agency, and literacy.

In "Mapping the Questions," Jessie Moore reminds us that too much of a focus on curricular and school-based learning fails to account for all of the ways in which writers learn about writing. As she puts it,

Existing studies primarily focus on academic contexts, overlooking students' many nonacademic activity systems. How do complementary, parallel, and intersecting activity systems impact students' shifts among concurrent activity systems, as well as from school to professional activity systems? Do students have access to other tools acquired in other activity systems that faculty should encourage students to access to facilitate transfer in the academic activity system?

The work of Chris Anson and Paul Prior approaches the complexity of such questions. On one hand, they note how sedimented knowledges about writing form part of the bedrock of what students know about writing as they transition to post-collegial composing ecologies. This anticipated knowledge provides a framework for them to understand how writing processes work and the value of being aware of different rhetorical situations. On the other hand, anticipated knowledge can also lead to frustration or confusion when professional environments do not mesh with participants' expectations, as professional writing researchers such as Patrick Dias, Aviva Freedman, Peter Medway, and Anthony Par as well as Anne Beaufort have demonstrated. Encountering the unexpected complicates the transfer of academic writing skills and strategies to professional and personal spaces, a complication already noted by Chris Anson in his auto-ethnographic study, "The Pop Warner Chronicles." He argues that

[o] ur conceptions of transfer must understand writers' experiences as involving much more 
than knowledge of genre, content, rhetorical situation, or process. To them we must add less explored writerly factors such as language preferences, the degree to which certain habits and practices have become sedimented, and aspects of writers' identities, cultures, and prior experiences in particular communities. (539)

We concur that such sedimented habits and practices are vital to consider when attempting to trace writers' developments across multiple ecologies of composing, but we would add to that sedimentation the encounter with the unexpected that challenges the writer to adopt new identities or adapt their existing identities as writers.

One way to attend to these developmental paths is to consider how writers make connections across different writing situations and across extended periods of time. In "Inventing Metagenres," Heather Lindenman argues that writers forge "idiosyncratic, action-oriented metageneric connections" across different domains and that those emerging understandings of how genres work in different contexts maps out developmental processes not accounted for by transfer models of writing. Her argument is in part a methods argument. She suggests that composition studies keeps discovering how writers see differences between schoolbased writing and professional writing, because researchers keep asking them about how these situations differ from one another. Drawing on close analysis of her qualitative data, Lindenman points out how upper-division undergraduates apply, adapt, and extend their prior knowledge about "We concur that such sedimented habits and practices are vital to consider when attempting to trace writers' developments across multiple ecologies of composing, but we would add to that sedimentation that the encounter with the unexpected challenges the writer to adopt new identities or adapt their existing identities as writers." writing when working in new contexts. This development of knowledge about metagenres, connections among genres, and writing for different audiences foregrounds how writers are making their own connections across writing situations.

Further, building on and extending earlier work around "student's right to their own language," scholars such as Carmen Kynard argue for curricula that not only include but re-vision themselves to honor the diverse experiences-and concomitant epistemologies—of diverse cultural groups. In her own classrooms, Kynard encourages students to "put some stank on their writing"- that is, to engage in the kind of writing that is not about "delivering a nice, tidy, clean product to a teacher, and composing a white self that has rid itself of racial emotion." While Kynard does not evoke the language of transfer explicitly, we can understand her pedagogical interventions as honoring the experiences and lives of her Black students by encouraging them to work, think, and write across the boundaries of school and home, so that cultural epistemologies come to impact and reshape writing in formal educational settings. ${ }^{2}$

Similarly, J. Estrella Torrez, Santos Ramos, Laura Gonzales, Victor del Hierro, and Everardo Cuevas, in "Nuestros Cuentos: Fostering a Comunidad de Cuentistas Through Collaborative 
Storytelling with Latinx and Indigenous Youth," consider a youth-oriented storytelling project that encourages Latinx and Indigenous engagement with children's literature as a way to encourage them to write and publish their own collaborative narratives about their lives and experiences. Torrez, Ramos, Gonzales, del Hierro, and Cuevas understand such work as empowering young writers while also helping them "build relationships across linguistic, cultural, age, and educational boundaries" as they work with each other and their adult and university sponsors. Transfer in the light of such vital projects seems less like preparation for skills transfer and more like a complex move across multiple domains-professional, educational, community, and cultural.

In an attempt to synthesize work across these different conversations, we recognize and value the impact that formal curricula can have on writers' to address the difficulty of designing curricula to foster such transfer, but the work of Lindenman; Kynard; Torrez, Ramos, Gonzales, del Hierro, and Cuevas; and others prompts us to wonder if it is possible to approach the scene of transition generatively by focusing less on issues of transfer from one domain to another and more on processes of navigation and orientation across multiple domains. For instance, we wonder what happens when we consider how writers, after they have left their collegiate training, begin to draw from multiple domains of knowledge and experience about writing and communicating, sometimes in unexpected and idiosyncratic ways? Lindenman; Kynard; and Torrez, Ramos, Gonzales, del Hierro, and Cuevas remind us that writers are often far more creative in pulling and stitching together not just sources of inspiration but also concrete ways of making and communicating meaning in a variety of contexts. Transfer studies have tended to emphasize movement from curricular-based learning environments toward professional contexts. But Lindenman; Kynard; and Torrez, Ramos, Gonzales, del Hierro, and Cuevas, as well as the participants we describe in our study, have shown us powerfully how non-curricular contexts can spark creative and innovative approaches to complex literacy tasks. Moreover, as our participants move increasingly away from their college years, they often re-orient themselves towards new ways of writing, thinking, and feeling their way across unexpected domains of knowledge about writing, both to address writing tasks as well as to explore possibilities for writing that they hadn't earlier considered-or thought possible. We call this complex process of orienting and re-orienting wayfinding.

In our study, the participants were asked to consider how their writing is developing, and this act of anticipation was certainly informed by the writing curricula they were experiencing or had experienced. At the same time, we will see in our discussion below how negotiating the paths between anticipated knowledge and the unexpected often produced tensions for our participants, prompting us to re-orient our own understanding of developing writing knowledges away from curricular and sedimented knowledge. At least two further dimensions of our participants' discussion of their writing necessitate that we begin to think beyond transfer models. First, these participants are all alumni, talking about their writing practices three or more years after graduation; their understanding of writing has been impacted and shaped by multiple experiences that suggest less a transfer from one domain to another and more a complex ecology of recursive, expanding, multivalent, and unexpected encounters with writing. Second, these participants often talk about the choices that they have to make to respond to new writing challenges, as well as their desires to pursue 
writing in different contexts, including personal, civic, and cultural; that is, they articulate an everdeveloping and shifting sense of agency vis-a-vis their writing. Their responses, then, reflect their attempts to navigate consciously through a complex landscape of communicative practice, and the themes that participants highlight often signal how they are orienting themselves in that landscape.

We call this wayfinding - a concept that allows us to recognize some of the complexities that previous scholars have noted while also providing a way to map multiple transitions, transfers, orientations, reorientations, and recursivities in the writing experiences of students and alumni. In these landscapes, participants may seek established signposts by which they orient themselves to communicative practices; however, their accounts frequently emphasize serendipity and idiosyncrasy. As such, we hope to avoid promulgation of the "worlds apart" problem that Baird and Dilger identify while also mapping out a robust accounting of writers' experiences.

\section{The Wayfinding Project}

Here we present several robust accounts from a pilot study we have conducted. We have found that these accounts of writing experiences map complex developmental paths that show us the navigations writers undertake in post-collegiate environments. The focus group interviews we report on in this article come from an IRB-approved study that we have been using to develop open-ended questions that ask participants to reflect on the following: their experiences with writing both in and beyond college courses; what they have learned about writing since graduating; what writing they have found meaningful; instances when they have employed different forms of writing to fulfill a purpose; and what conversations about writing they have shared with family members, co-workers, and friends.

To conduct this pilot, we sent an invitation to alumni lists from UC Davis, UC Irvine, and UC Santa Barbara. Twelve respondents volunteered to participate during the first year, and this article reports on the focus group sessions with these alumni. The focus groups met with two interviewers via Zoom, a digital conference platform. To maintain anonymity, only an audio recording of each focus group was digitally preserved and then later transcribed using the service Rev.com. Each focus group interview lasted between 30-60 minutes. We have been using a recursive, grounded-theory approach to identify and code for emergent themes that characterize this wayfinding. Here, we have selected and analyzed comments from seven of the twelve participants, as these comments best exemplify three of those emergent themes: encountering the unexpected, navigating career plans and paths, and seeing beyond boundaries. These telling cases reflect the physical distribution of our campuses' alumni-who live from coast to coast-as well as the wide variety of professions, avocations, and personal goals that our alumni pursue. A limitation of the pilot project was that we did not systematically collect demographic information for the focus groups participants. ${ }^{3}$ Nonetheless, given that our campuses are designated Minority-Serving Institutions, the diversity of our participants reflected the racial and ethnic diversity of University of California students. ${ }^{4}$ Participants typically introduced themselves via their professional (writing) identities, and we follow suit in introducing them in the following paragraphs. The participants' names are pseudonyms. 
Two of the participants, Susanmarie and Wendy, work in education. Susanmarie is a high school French teacher. She talked enthusiastically about her AP French students, and we were particularly struck by her discussion of how she crafted short speeches for graduating seniors who had completed her AP course. Wendy is a curriculum developer working on K-6 math materials; when asked about her professional writing, she discussed how she developed "digital lessons with supplemental print components" for classroom teachers. As a writer, Wendy was aware of how moving across print and digital media impacted her and her readers in professional, personal, and civic contexts.

Another alumnus who explicitly discussed how writing for different media and using different platforms impacted his experiences as a writer was Daniel, a tech journalist. Daniel's work involved writing about "technology and culture association with technology. So apps, start-ups, Facebook, Google, all that stuff ... I have written on a lot of tangentially tech related topics including gaming, culture of gaming, and coding." Kaya, who has worked in multiple positions in publishing, also found the different contexts for writing to be important, and while she was aware of the importance of media, particularly email, she also talked about how being perceived as "the writer" or "the English major" in work lead some to consider her "the comma girl." She notes, though, that it's really a passion for language that drives her stance towards writing and its importance. Kaya noted that one of her experiences post-college was learning "that people can see the language very differently."

Two other participants, Teresa and Tim, work in advertising and marketing. Teresa is a copywriter for an advertising agency. She noted the tensions between writing professionally and writing for personal satisfaction; she said, "I think writing as a hobby was something I used to do before I started writing professionally. I think it's really just my brain power shuts down after writing for work all day, but I used to try to write just for myself. I'm really bad at keeping up a blog, but I used to just write short stories, just things like that. But that's really slowed down in the past five years or so." Tim also

"Kathy saw her post-college writing as mostly professional, and in particular, she believed that her professional writing was 'really based in research and analysis.' She had worked for defense contractors and for non-profits. When recounting her work history, she traced a trajectory from 'taking notes in meetings' into the more extended analytic writing she was doing in her current position." spoke eloquently about the tensions of navigating among personal writing interests and writing as a major part of his career. Certainly workplace writing occupied a majority of his writing experience after graduating; however, Tim also discussed how connecting with family and friends via social media writing was meaningful to him. Kathy saw her post-college writing as mostly professional, and in particular, she believed that her professional writing was "really based in research and analysis." She had

worked for defense contractors and for non-profits. When recounting her work history, she traced a trajectory from "taking notes in meetings" into the more extended analytic writing she was doing in her current position. What was interesting is that she saw her early career work taking notes 
and summarizing meetings as a direct precursor of the more advanced reports she was writing. She talked about how taking minutes was "trying to get high-level bullet points out of some of those [minutes], sticking with main ideas, and then creating some deliverables; more for the executive level internal with the company, then client facing. But it was a good segue into what I'm doing now."

Although we are still in the early stages of much more extensive data collection, these initial interviews have provided telling cases that illustrate how alumni navigate multiple writing domains and career pathways, as well as how they continue to learn about writing. We turn now to an examination of the particular themes that have emerged out of our discussions with these alumni.

\section{Encountering the Unexpected}

Many of our participants described a sort of collision between what they anticipated and the actual writing they engaged in beyond their college courses. This collision created tensions, but the ways in which participants described navigating through those tensions show how anticipated knowledge and unexpected experiences shape an individual's writing development, or their postcollegiate wayfinding in writing. If, as Bazerman, Applebee, and Berninger claim, "successful writing development cannot be defined as movement toward a standard" (381), then the participants in this project are helping us map how writing experiences, writers' understandings about their own writing, and professional writing curricula require people to find their way.

Some examples offer a sense of the challenges created by the unexpected, as well as the possibilities the unexpected provides for developing new knowledges about writing. In one case, Susanmarie, who works as a high school AP French teacher, remarked at length about the challenges she faced when writing end-of-year speeches to deliver to her students. For her, such speech making was clearly amongst the most meaningful writing experiences she has had:

I would say it would be the speech that I write to my AP students at the end of every year. I'm the only French teacher, so they have me for three or four years; so, it's hard to say goodbye. $^{5}$

At the same time, Susanmarie noted that she had never learned how to write speeches in college, having taken no speech or communication classes. The unexpected need to produce and deliver a kind of writing that had not been taught prompted a creative turn to other media-hybridized media, we note-to develop some self-sponsored skills and strategies. Certainly this participant's rhetorical ability to seek out appropriate models likely attests to her academic training, at least in part. She claimed to be proud of her academic writing, in particular a master's thesis she wrote for her graduate work in French. On one hand, we might understand writing abilities here as mobile, constituting not a straight line from academic to professional writing, but one including a byway through analyzing, mimicking, and adapting televised speeches. In this case, then, sedimented abilities met changing needs. On the other hand, we recall that Susanmarie was responding not to a question about adaptability of prior knowledge but about her most meaningful writing experience. What interests us is how Susanmarie orients herself within and constructs her writing context, realizing that she needs to seek out models in an extra-curricular and extra-professional space to do 
something with writing that is meaningful for her.

The unexpected also occurs in situations in which individuals not only need to address a new and unanticipated professional task but find themselves wanting to use writing to explore, confront, or communicate about a personal experience. Tim, also responding to the question about the most meaningful writing he had done, spoke movingly about the sudden death of his dog after he had moved across country to take a new job:

So I just relocated for my current role with my company [...] so the weekend right before I relocated, I got news from my family back home that our long term family pet, our dog, had passed away or had been put down because he was almost 18 so didn't exactly not see it coming. But anyway with this relocating and all that it was not really top on my mind so a couple days into being here in Philadelphia was just sitting in a café and it started to hit me. So I wanted to just kind of reflect on that and write something regarding that and also as part of being over here, I'm not a big social media person normally but I set up an Instagram account so I could keep in touch with my friends back home or back in Irvine, and so posted something or was trying to post something and I pulled some of the old photos of Shadow [who] was my dog.

Tim describes wanting more space and time to write creatively or personally; he had been an English major and, while enjoying writing in his new professional role in marketing, also derived pleasure from more creative forms of writing. The death of his dog, a loss exacerbated by his distance from family and friends, prompted him to turn to writing on a social media platform, Instagram. Composing becomes hybridized with pictures of Shadow in the creation of an impromptu memorial where this alumnus explores and shares his feelings. As in the preceding case, sedimented knowledges and identities become challenged by the unexpected, such as personal loss. Alumni use writing to express themselves and connect with others as well as for professional purposes.

Given the challenges of the unexpected, which include unanticipated needs to compose in particular genres or to address specific situations, we should not be surprised that some participants spoke of understanding writing as an ongoing form of inquiry, a modality that they use specifically to discover, explore, and generate thinking. Kathy was particularly eloquent when talking about the development and use of writing as a form of inquiry:

$[W]$ riting became a learning tool for me. So instead of just writing what I had learned, I wrote to learn. So I would read, and I would read, and I would read, and I would read, and then I would take everything, put it together in my brain, reframe it, and write it out. And that helped me to actually figure out how to retain everything. So instead of just writing down notes of whatever it is you hear, whatever you see, you take stuff in, you internalize it, and then you can produce it in the form of writing - in a way that makes sense to youbecause it's your composition, word for word. So that helped me really understand the power of writing and the power of, like I said, writing as a learning tool, instead of just as showing what you learned.

Writing-to-learn might appear to be primarily a college experience. But Kathy has carried this understanding of writing over into her work life and uses, for instance, a legal pad to make 
copious notes and as a way of discovering connections. She suggests that sometimes she writes to communicate with others, but that sometimes she writes to connect ideas:

I would say writing directly translates to communication. I would think writing is connections. This is harder than I thought. I would say this. Sometimes you write for you because it helps you to make connections in your own brain. Or, sometimes you write for other people to help them make a connection between what's going on in your brain and what's going on out there. That's the answer.

Another participant described the use of bullet journaling to help her make "big decisions," even if she knows what she would like to do. She finds it helpful for her to "put out multiple ideas" to see what her choices are. In the process, Kathy is showing us how our participants identify different tools of writing - and perhaps some tools that lie outside most typical curricular paradigms, such as legal pads and bullet journals-as crucial to their ways of orienting themselves around significant connections and points of decision.

\section{"A compelling finding from our study has been the extent to which participants did not anticipate how valuable-and nuanced-writing abilities would be across multiple contexts, including professional and career pathways they had not considered or even imagined."}

The dynamics among our participants' anticipated knowledge and unexpected experiences underscores Brandt's; Bazerman, Applebee, and Berninger's; and Anne Ruggles Gere's calls for a holistic approach to understanding writing development over multiple years. Mapping the dynamics among anticipated knowledge, the

unexpected, and wayfinding allows us to illustrate how writing development during and in the ten years following college far exceeds what Bazerman, Applebee, and Berninger call testable skills. Examining the ways in which participants discuss these experiences extends current insights about how students' and alumni's writing develops over time and in relationship with education, career, and personal experiences. Our participants' reports confirm Brandt's claim that writing is "eclipsing reading as the literate experience of consequence" (3). Further, alumni's accounts of post-college writing experiences trace contours of writing that are associated not only with work but also with a complex set of personal, affective actions and transactional activities.

\section{Navigating Career Plans and Paths}

A compelling finding from our study has been the extent to which participants did not anticipate how valuable-and nuanced-writing abilities would be across multiple contexts, including professional and career pathways they had not considered or even imagined. While some either planned on, or were already in, early career positions as professional writers, many were in the process of becoming social workers, psychologists, teachers, or professionals a range of other careers. In each case, writing occupied a significant amount of time while they were in school, and 
then became important in terms of their workplace experiences. As they recounted these transitions, our participants themselves articulated different understandings of what writing means in different contexts, as well as how they oriented their career pathways accordingly. They ascribed different degrees of importance to these understandings of what writing means, depending on how people around them assessed their writing and came to value their writing abilities.

For instance, here's how Teresa, one of the alumni who worked in advertising and marketing, articulated the value of writing in a range of contexts, especially professional ones:

[I]t's so important to get the right words and the smart words out there, because it's such a crowded space that I am always trying to get what is that core, golden nugget and not wanting to skimp on quality because I only have a limited amount of space.

Many of the alumni report writing regularly for their jobs, including emails, proposals, presentations, as well as writing for different "channels" and adapting one's writing to different channels, platforms, and mediums. Kaya, who worked in publishing, noted the extent to which good writing abilities have helped her stand out from others:

I think in my case in particular coming out of the English department at [...], going into a graduate program in publishing and writing, and then working in publishing for two years I was always surrounded by a lot of people who really knew what they weredoing, really knew the power of a word, and a power of this well constructed sentence and the impact that that can have.

And then about three years ago I transitioned into nonprofit work and as soon as I kind of stepped into that arena suddenly the fact that I could string three sentences together became this deified skill, people were really impressed by it and I'm like, that's just writing.

For Kaya, writing is a professional skill that her co-workers valued. It's noteworthy that her ability as a writer was recognized both in publishing and at a non-profit. However, she notes a difference in how writing is seen in the two professional spaces: In publishing, writing is about "the power of a word, and a power of this well constructed sentence and the impact that that can have," while in the non-profit writing is more of a defied skill that is useful because it benefits the larger goals of the organization. Recognizing how writing is valued differently in different contexts is an important developmental step, and it is one that seems to solidify or gain depth and nuance following graduation.

For these young people, academic preparation laid important groundwork for helping them find their way through future writing tasks and challenges. For instance, understanding writing as a process has helped, even as those processes have had to be adapted to "real-world" contexts. This finding doesn't just bolster Brandt's claim about the "rise of writing" but also allows us to trace students' more nuanced development of their writing abilities, as well as their own understanding of their writing abilities, in post-collegiate environments. As we will see, that development encompasses both building on previous academic preparation and learning from non-curricular experiences.

Our participants' approach to audience offers a telling case in point. A skill that has become commonplace in many composition and writing curricula, audience awareness builds in complexity and nuance as these young people move through different writing ecologies, particularly professional ones. Indeed, for many of our participants (so far), good writing is characterized by attention to 
audience that seems to cut across numerous writing careers and professions. With such acute attention to audience, then, the kinds of writing that these alumni have done, mostly professionally, seems more "pointed," direct, immediate, and focused on getting a particular message across. Tim and Daniel both spoke to this issue. Tim, who works in marketing, noted that

One of the things as my roles have changed over the past couple of years that I've noticed change with my writing and my approach to writing is just being much shorter, much more to the point, just kind of as you enter certain roles you just don't have time for various things and it's just about how do you get the bare essentials of here's what needs to be done, here's who needs to do it across and maybe some of the niceties and things like that they go by the wayside because they're just not that important in the grand scheme of things.

Likewise, Daniel, who is an active journalist, saw audience and message being impacted by time and time-pressures; he pointed out that,

[in] some sense, space literal short of word counts, but also, space timewise. Space in their schedule. Frequently pushed to get a piece, read it, process it, rewrite it in an hour, say, or even half an hour. And sometimes that was by editorial direction and sometimes that was personal prerogative. Say, if I was being paid per post.

As a journalist writing for a variety of online platforms, Daniel's concerns were about audience, message, and time-and they reflect editors as a first audience and then the wider readership of magazines, newspapers, and online platforms. In fact, when asked about their own definitions of writing, participants seemed to locate audience awareness at the core of their definitions of writing. Expanding on her ideas about audience awareness, Kaya said:

I think like whether it is something on social media, if you're writing something for work, if it's just an email, if it's a proposal, if it's something like that you're still trying to communicate a message and I think that's at the core of the definition, at least in my mind.

Put simply, for Daniel and Kaya, audience awareness is writing. They mark this insight about the centrality of audience awareness - their growing understanding of how audiences push and pull on writing situations and genre conventions-as a particular experience of writing while finding their way professionally. And as audience awareness becomes more complex and nuanced, these alumni's understanding of themselves as writers also increases and evolves.

Like Daniel and Kaya, two of the participants in Lindenman's "Inventing Metagenres" emphasized the importance of audience awareness. In one of Lindenman's cases, Preston discussed how he used a "conclusion first" move "to appeal to an audience uninterested in a slow-moving academic approach." Lindenman goes on to note:

Preston acknowledges that this "conclusion first" move looks different in different genres, but the common structure is the same, and the cause for the structure-the need to appeal to readers on a tight schedule or who may not read the whole piece-is consistent across instances.

Lindenman's key point here is not only, or even mainly, that Preston is aware of his audience, but rather that he is making connections about how structures work across contexts and genres. Likewise, Lindenman's participant Izzy describes how two very different pieces of writing develop 
"illocutionary effect[s]." Izzy reports on a grant application and a Tumblr review of the play Peter and the Starcatcher. Her discussion reveals analytic connections that upper division undergraduates are already making across writing situations. In our study of alumni working post-graduation, writers appear to become even more aware of their own agency as writers who can shape others' perceptions. These successful writers analyze their writing contexts, consider their audiences to have primary places within those contexts, and shape their writing accordingly.

Wayfinding occurs in very concrete ways as these young professionals consider next steps in their careers and ponder how writing will fit into-and transform along-those paths. Some participants described complicated pathways in their careers and in their development as writers. For these participants, universes of possibility are still open-living pathways, not dead ends or lost highways. Some of the focus group participants expanded on this idea of a wide range of potential, which seemed to reside in the act of writing itself. As Kaya eloquently put it,

So I think writing for me, even if it's personal or if it's something that I'm sending to other people, it's a way for me to convey my thoughts more effectively and coherently, because I can plan it and edit it more. So usually, if I want to convey something very important, I will write it in an email to somebody, as opposed to call them or talk to them.

For Kathy, who has worked at a number of consulting firms, writing opened up other kinds of potential, specifically job and career pathways:

[T] he last couple of years especially, going through job applications, one of the things about having writing as a tool is that my writing precede me. So when I would step into a room and go through an interview or something like that, there was already this preconceived notion that they've read my cover letter, and I sound great on paper, and hopefully I show up just as well in person, and I can have that personal interaction with them; it's kind of like a seat warmer. [Potential employers] had an idea that I was gonna be great for very specific projects that have really high stakes, and then they also felt like I was gonna be on the fast track, and not everybody goes into the company that way. Just because of the way I presented myself, I got that opportunity.

While career pathways open up for some participants, others describe creative writing projects in which they are clearly invested and through which they see potential to expand their own understanding of writing and what writing can do:

So it's been about 10 years now that I've been working on this. It's kind of my incubated baby that I work on every once in a while. It's becoming less frequent the busier I get, but it started in a hotel room, on one of the little pads of papers that they give you and the little pens on the nightstand. So that's where it started, and it's grown into this-I don't even know how many pages I've written-but it's an enormous file, and I think that my writing has probably grown through this more than through academic writing in general because I want to refine every thing about it. Like I said, it's like my incubated baby, so it continues to evolve. I've probably done upwards of 15 drafts of the first chapter of it. You know, it's a point of relaxation for me. It puts me in a different frame of mind. So it's been a really incredible experience, and you probably will never see it on the market, so don't look for it. 
But it's meaningful to me, and I think that it's helped my academic writing so much, because you get a lot of practice.

Kathy emphasizes that she's not transferring school knowledge to this project, but rather working the other way around. Her ongoing writing practice is an incubator that she describes as having a non-school start. It is an orientation, a lever, and a value that does not assume instructional goals, or even previous instruction; rather, Kathy's writing in this case is motivated by personal satisfaction, by an impulse to create.

At the same time that participants revel in their creativity and professional acumen as communicators, others noted what the copywriter Teresa identifies as a "danger" in writing: the ease with which it is publishable online:

I think the only thing that I would say, and this is something I've been thinking a lot about is how different the world is today and how writing is so accessible, and on the flip side, how that makes it so dangerous. I think now everyone can have an anonymous voice with social media. Everyone can publish with these self-publishing blogs. And I think because of that, it's even more important than ever before to be able to articulate ideas, to say what you want to say, and also take ownership of what you're saying.

Such "danger" necessitates the development of writing abilities, including the need to practice care and awareness when writing and publishing. Audience awareness is a key aspect in this development, but the development of writing abilities also reaches beyond just audience awareness and includes the relationship of writers with audiences. Given such accounts from alumni, we, as researchers, need to recognize that these potentials, particularly these forms of agency and creativity, are not only important but vital for students and alumni. As a concept, wayfinding encourages us to account for this process of navigating among professional and personal identities and desires.

\section{Seeing Beyond "Boundaries" of Writing Contexts}

In our focus group discussions, attention to issues of audience often pivoted into discussion about the differences between academic and non-academic writing, as well as how writers navigate unexpected opportunities to blend the two or cross genre boundaries in creative ways-experiences that contribute to these participants' agency, and identity, as writers. As Michele Eodice, Anne Ellen Geller, and Neal Lerner explore in The Meaningful Writing Project, it is important for students and alumni to imagine the writing that their future selves will do, as agency, personal identity, and writing contexts are intimately intertwined. As we consider how these writers blur the boundaries among different writing situations, the different "containers" for writing, we recall Lindenman's concept of metageneric connections. Lindenman's concept provides a way of explaining how writers work not only across different contexts, but also how they develop their own idiosyncratic understandings of writing. Her work resonates with how scholars in the field are increasingly pointing out the many ways in which radically divergent modes of composing and communicating actually have much to say to one another. In "DJs, Playlists, and Community: Imagining Communication Design through Hip Hop," Victor Del Hierro uses a case study of a hip hop community as a model for "creating, 
curating, and maintaining the flow of information" (2). For Del Hierro, the range of creative, archival, and technical modes that intermesh to produce hip hop offers a powerful model for connecting professional, personal, and inclusive information and work practices. Del Hierro's turn to hip hop is an unexpected but welcome move to argue how communities are engaged in the kinds of communication practices that can inform a range of complex practices across multiple contexts.

With such research in mind, we asked our participants explicitly about how they combined different kinds of writing to fulfill specific purposes. Teresa said:

I think for me, when I went through undergrad and graduate school for myself, writing was always how to get an idea across. And in the world of advertising, I quickly had to learn not only getting the idea across but getting it across to an audience, and also, within a container.

Wendy, who works as a curriculum developer, pointed out that her daily writing post-college had a range of audiences:

In my day-to-day, I will go between writing kindergarten content all the way through fifth grade content, and not typically in one day will I write for all six grades but I have. I have written for kindergarten and then bumped up and written for third on the same day, and then to that same degree I'm then drafting emails to colleagues.

For Wendy, such tasks were not single tasks with multiple audiences but rather discrete tasks with discrete audiences. Wendy had to recognize the boundaries of the different writing situations, particularly as they were defined by relationships with different audiences beyond the divide between academic/non-academic. Tim's work in advertising gave him a particularly refined take on both seeing the boundaries of a writing situation — and seeing beyond them. He said,

So really just making sure that we were understanding who the audience is, not just in terms of what people they are but also what is their time constraint, what is their interests, what is the attitude or the tone that they might be approaching something with at that moment based on where it's located or where they're likely to come across that material.

Tim's comments focus on audience and the time constraints of different audiences, and like Teresa, he sees time and attention as creating boundaries that serve as containers. His ideas about boundaries signal an awareness that effective writing often occurs in and through discrete forms and genres.

Awareness of one's composing "container," which can include platforms of communication, is important to these participants; even in personal communication, some participants think through rhetorical situations carefully. This awareness also extended to multimediated composing platforms, where different conventions and expectations form in relation to particular technologies. Kaya's knowledge of publishing and the publishing industry came into play here when she said:

It ended up being a situation where we had had enough awkward miscommunications that I sat down and talked to a friend about this and we realized that there wasn't really an aggression behind her words, it's just the way that she conceived the purpose of this message, of the text message. It was really just a means by which to communicate $\mathrm{X}, \mathrm{Y}$, and $\mathrm{Z}$ information and didn't really have the rest of this baggage connected to it. So for me learning through weird trial and error that people have different emotional connection to 
language and how they use it in their life was something that I hadn't really expected before because again coming out of this bubble where people view language in a very similar way, that way that I did.

Kaya here not only considers different composing platforms but also uses the metaphor of the "bubble" to signal her sense of containers and boundaries. Such interactions reveal some development of meta-reflective abilities with regard to the rhetorical situations enabled, or challenged, by both different communication platforms and different contexts for composing.

In addition to thinking about genres and containers, the participants were thinking about themselves as writers. One of the striking findings from the interviews was how participants articulated writing as a form of "branding." They saw "branding" as a way to navigate and understand the different rhetorical and creative purposes to which writing can be put. Teresa and Tim commented in particular on the relationship between writing and "branding" or other forms of business, corporate, or advertising communication needs. In these cases, writing becomes part of a larger communication project on which multiple people are working. Teresa said:

I work for an advertising agency, and so I sit on the creative department. I work with designers and together we create these visual and messaging stories for our clients. So, a lot of it is around branding, a little bit is around ad writing, but mostly it's helping brands unearth what those true authentic stories are to who they are as a brand and what is the best way to express that to the audience that they're targeting? So that's the poetic version of what I do.

Our participants reported having to navigate among expectations about writing outside of college and their actual experiences writing in those environments; in some ways, the ability to write allowed Tim to "brand" himself as the writer in his organization:

I had sort of a similar experience in my past role, or one of my past roles was being kind of sought out as, oh he's the guy with an English degree, right. Somehow that made me capable in a way that they weren't. It didn't really, I mean it does in some ways but really the English degree is more about critical analysis and being able to understand that kind of thing and this was more about just putting together, stringing together sentences, right. And it was really interesting to see people I guess struggle with what I would take for granted as such a basic thing. But they would make a point like, oh Tim's the person who will help you out with that.

Such responses highlight participants' nuanced and multifaceted understandings of what writing is; participants see it as both varying from context to context as well as having consistencies across contexts. Their answers suggest that these views are not contradictory but rather mutually supportive. Participants did not always understand what they were doing, but they muddled through it anyway. Wayfinding is a way of capturing this ongoing muddling.

\section{Writing and Wayfinding}

Given the importance of writing and literacy in a range of contemporary workplace, personal, 
and civic environments, as well as the need to know more about the experiences of graduates "in the world," scholars in the field are taking a longer view of writing development, challenging our field's commonplace understanding that collegiate learning about and experiences with writing prepare students sufficiently for post-collegiate communication ecologies. Two of the key findings in Anne Ruggles Gere's Developing Writers in Higher Education: A Longitudinal Study are that writing development is a continual learning experience (185-246, especially 185-192) and that it "precedes and extends beyond college" (247). In The Lifespan Development of Writing, Bazerman, Applebee, and Berninger have argued that writing development is an integrated part of learners' life experiences and that a multidimensional approach to writing development that considers how individuals change over time may yield increasingly accurate and nuanced understandings of writing development. They argue for a change from current approaches that foreground understanding writing development in terms of performance in discrete and situated context(s) rather than writers' development over time.

Many teacher-scholars in our field approach the challenge of understanding writing development over time from the perspective of what educators and writing instructors can do in the context of college courses to prepare students for what comes next. Christopher Jerde and Mark Taper, amongst others, advocate for intensive writing training, particularly in the sciences, as vital preparation for students hoping to enter scientific and technical fields; training in first-year composition is simply insufficient for the demands of the contemporary workplace. The emergence of writing majors has interestingly tracked these concerns with writing skills development, providing students

"Ultimately, wayfinding has allowed us to consider how an individual writer develops over time in multiple settings. Our research shows us the variety of ways that participants can signal their idiosyncratic use of metagenres, their innovative approaches to writing, and their development of new and even unexpected knowledges about writing." opportunities to focus even more attention on writing and composing as central features of contemporary employment, not to mention personal and civic life. Christian Weisser and Laurie Grobman note that "[i]t should come as no surprise that writing, communication, and related activities are central features of a rhetoric of professionalism" amongst students they surveyed who had graduated from a professional writing major

(47). In line with such findings, and in response to similar kinds of studies and data, TJ Geiger and Kara Alexander, Michael-John DePalma, Lisa Shaver, and Danielle M. Williams have documented ongoing curricular changes to writing major programs, designed to keep track of evolutions in the writing lives of graduates. Most recently, Claire Lauer and Eva Brumberger trace how contemporary workplace writing involves revision and redesign depending on audience and delivery media; they ask how collegiate writing programs could better prepare students for these "responsive" workplaces where "writers must adapt to making meaning not just through writing, but across a range of modes, technologies, channels, and constraints" (635). We are mindful of these curricular needs, even as we are too early in our own data collection and analysis to posit what those curricular innovations 
might be.

More compellingly for us, our participants described how they are exploring and discovering new knowledges about writing, particularly as they encounter the unanticipated and the unexpected. As graduates are finding their way, they are deploying a mix of sedimented and newly discovered abilities and knowledges, some developed out of necessity. A writer might certainly develop techniques in her college courses and use them when she is working as an advertising copy writing and developing ideas about both personal and professional writing as "branding" and as acutely aware of audience needs and expectations. At the same time, she might just as readily discard some writing techniques as too academic for the quick pace of her work. Wayfinding captures these participants' experience of writing as it continues to develop across a lifespan. This ongoing development has several dimensions: the continuous potentialities in professional and personal forms of writing and writing situations, how writers deal with writing that crosses boundaries, and how writers encounter unexpected and serendipitous writing situations as creative rhetorical and personal opportunities.

Ultimately, wayfinding has allowed us to consider how an individual writer develops over time in multiple settings. Our research shows us the variety of ways that participants can signal their idiosyncratic use of metagenres, their innovative approaches to writing, and their development of new and even unexpected knowledges about writing. Focusing on their own articulated wayfinding allows us to identify how participants articulate those idiosyncratic knowledges-and, interestingly, what they orient themselves towards as they do so, whether those orientations are complex understandings of themselves as writers or complex understandings of when and how the boundaries of writing contexts work, hold, shift, blur, or transform. Sometimes these nuanced understandings of writing cultures may align with what we, as writing experts, would anticipate (i.e., the well-signposted, more traditional understanding of writing from our curricula). Sometimes, though, they surprise us, especially when participants are drawing on writing knowledges they have acquired in contexts often invisible to our curricula. Wayfinding focuses our attention on how writers consciously navigate and claim agency in the complex, albeit messy-and often idiosyncratic-paths they take in post-collegiate writing contexts. As we gather more data, we hope to trace more fully the dynamic processes of writing that continue to develop after graduation. 


\section{NOTES}

${ }^{1}$ By using "knowledges" instead of "knowledge," we emphasize that our participants offer various definitions of and approaches to writing across different contexts.

${ }^{2}$ See also the work of Adam Banks. In Race, Rhetoric, and Technology: Searching for Higher Ground, he asserts that any attention to the use of writing in complex digital spaces that does not take into consideration how race (and racism) shape normative uses of language is fundamentally damaged. More importantly, as Banks attests, scholars attentive to contemporary forms of writing, especially writing composed through digital platforms, should attend to the creative and innovative ways in which individuals and groups from varied cultural backgrounds use language and work through writing to share experiences, disseminate insights, and offer social and political critiques

${ }^{3}$ The study also included an anonymous survey of current students (not reported on in this article) that piloted demographic questions regarding race/ethnicity, gender identity, languages, and educational history. We will draw upon our experiences with these questions when we launch the full study later this year, and we will collect such demographic data for our focus group alumni as well.

${ }^{4}$ Hispanic-Serving Institution (HSI) and Asian American Native American Pacific IslanderServing Institution (AANAPISI)

5 Quotations from the focus group interviews are occasionally edited for clarity. Ellipses in brackets indicate an elision in the transcription that we have made; ellipses without brackets indicate that the speaker has paused momentarily in talking. Words within brackets indicate edits for clarity. 


\section{WORKS CITED}

Alexander, Jonathan, Karen J. Lunsford, and Carl Whithaus. “Toward Wayfinding: A Metaphor for Understanding Writing Experiences.” Written Communication, vol. 37, no. 1, 2020, pp. 10431. https://doi.org/10.1177/0741088319882325

Alexander, Kara, Michael-John DePalma, Lisa Shaver, and Danielle M. Williams. "Approaching the (Re) Design of Writing Majors: Contexts of Research, Forms of Inquiry, and Recommendations for Faculty." Composition Studies, vol. 47, no. 1, 2019, pp. 16-37.

Anson, Chris M. "The Pop Warner Chronicles: A Case Study in Contextual Adaptation and the Transfer of Writing Ability." College Composition and Communication, vol. 67, no. 4, 2016, pp. 518-49.

Baird, Neil, and Bradley Dilger. "How Students Perceive Transitions: Dispositions and Transfer in Internships." College Composition and Communication, vol. 68, no. 4, 2017, pp. 684-712.

Banks, Adam J. Race, Rhetoric and Technology: Searching for Higher Ground. National Council of Teachers of English/Erlbaum, 2005.

Bazerman, Charles, Arthur N. Applebee, and Virginia W. Berninger. The Lifespan Development of Writing. National Council of Teachers of English, 2018.

Beaufort, Anne. College Writing and Beyond: A New Framework for University Writing Instruction. Utah State UP, 2007.

---. Writing in the Real World: Making the Transition from School to Work. Teachers College P, 1999.

Bowen, Lauren Marshall. "Composing a Further Life: Introduction to the Special Issue." Composing a Further Life, special issue of Literacy in Composition Studies, vol. 6, no. 2, 2018. https://doi.org/10.21623/1.6.2.1

Brandt, Deborah. The Rise of Writing: Redefining Mass Literacy. Cambridge UP, 2014.

Brent, Doug. "Transfer, Transformation, and Rhetorical Knowledge: Insights from Transfer Theory." Journal of Business and Technical Communication, vol. 25, no. 4, 2011, pp. 396-420. https:// doi.org/10.1177/1050651911410951

Del Hierro, Victor. "DJs, Playlists, and Community: Imagining Communication Design through Hip Hop." Communication Design Quarterly, vol. 7, no. 2, 2019, pp. 28-39.

Dias, Patrick, Aviva Freedman, Peter Medway, and Anthony Par. Worlds Apart: Acting and Writing in Academic and Workplace Contexts. Routledge, 1999.

Eodice, Michele, Anne Ellen Geller, and Neal Lerner. The Meaningful Writing Project: Learning, Teaching and Writing in Higher Education. UP of Colorado, 2017.

Geiger II, T. J. "An Intimate Discipline? Writing Studies, Undergraduate Majors, and Relational Labor." Composition Studies, vol. 43, no. 2, 2015, pp. 92-112.

Gere, Anne R. Developing Writers in Higher Education: A Longitudinal Study. U of Michigan P, 2019. Jerde, Christopher L., and Mark L. Taper. "Preparing Undergraduates for Professional Writing: Evidence Supporting the Benefits of Scientific Writing within the Biology Curriculum." Journal of College Science Teaching, vol. 33, no. 7, 2004, pp. 34-37.

Kynard, Carmen. "Stank 2.0 and the Counter-Poetics of Black Language in College Classrooms." 
Teacher-Scholar-Activist, 9 Oct 2017, http://teacher-scholar-activist.org/2017/10/09/ stank-2-0-and-the-counter-poetics-of-black-language-in-college-classrooms/.

Lauer, Claire, and Eva Brumberger. "Redefining Writing for the Responsive Workplace." College Composition and Communication, vol. 70, no. 4, 2019, pp. 634-63.

Lindenman, Heather. "Inventing Metagenres: How Four College Seniors Connect Writing across Domains." Composition Forum, vol. 31, 2015, files.eric.ed.gov/fulltext/EJ1061560.pdf.

Moore, Jessie. "Mapping the Questions: The State of Writing-Related Transfer Research." Composition Forum, vol. 26, 2012, https://compositionforum.com/issue/26/map-questions-transferresearch.php.

Prior, Paul. Writing/Disciplinarity: A Sociohistoric Account of Literate Activity in the Academy. Routledge, 1999.

Torrez, Estrella J., Santos Ramos, Laura Gonzales, Victor del Hierro, and Everardo Cuevas. "Nuestros Cuentos: Fostering a Comunidad de Cuentistas Through Collaborative Storytelling with Latinx and Indigenous Youth.” Bilingual Review/Revista Bilingue, vol. 33, no. 5, 2017, bilingualreview.utsa.edu/index.php/br/article/view/294.

Weisser, Christian, and Laurie Grobman. "Undergraduate Writing Majors and the Rhetoric of Professionalism." Composition Studies, vol. 43, no. 2, 2012, pp. 39-59. 